\title{
Entrevista com Wilson Alves-Bezerra
}

\author{
Carlos Henrique Lopes de ALMEIDA* \\ Luciana Ferrari MONTEMEZZO**
}

Na seção entrevista do dossiê temático do volume II do número 56 da Revista MOARA, intitulado "Literatura, história e memória na América Latina", recorremos ao olhar do pesquisador que tem consolidado sua carreira em várias frentes, Wilson AlvesBezerra, professor da Universidade Federal de São Carlos, autor de livros sobre crítica literária, livros de literatura, ensaios, ficção, poesia e tradutor de literatura hispanoamericana (espanhol-português), tendo sido finalista do Prêmio Jabuti em 2009 nesta categoria.

\section{Considerando a sua formação em Letras e Literatura, aliada à prática tradutória e à indicação ao prêmio Jabuti, como avalia a formação teórica na área de Tradução?}

Acredito firmemente que a tradução literária é uma práxis - envolve sim conhecimento teórico, mas só faz sentido em ato. Quando me refiro à prática no caso da tradução não falo apenas de traduzir, mas de entender, como dizia o tradutor argentino do Ulysses, de James Joyce, que "traducir es el modo más atento de leer" (Salas Subirat). Além disso, traduzir envolve ainda a escrita literária também. Traduzir literatura é um ato de escrita paralela, como dizia Haroldo de Campos. A tradução é a um só tempo conhecimento das línguas, das culturas, e prática de leitura e escrita. A Universidade, certamente, é um local privilegiado para seu cultivo, mas a tradução literária e a reflexão sobre ela ocorrem muito também fora do ambiente universitário: penso nas diversas oficinas literárias, casas de tradução e nas redes subterrâneas de contato entre tradutoras e tradutores, vivos e mortos.

\footnotetext{
* Doutor em Letras e Linguística. Professor de língua adicional e literatura da Universidade Federal de Integração Latino-americana, no Programa de pós-graduação em Literatura comparada PPGLC-UNILA e do PPGL-UFPA. E-mail: carlos.almeida@unila.edu.br

** Doutora em Teoria e História Literária pela UNICAMP e pós-doutora em Tradução pela Universidad de Granada (Espanha). Professora no Programa de Pós-graduação em Letras/UFSM da Universidade Federal de Santa Maria. E-mail: lucesfm@gmail.com
} 


\section{O que pode nos contar do processo de tradução da obra de Horacio Quiroga para o português? Estabeleceu algum critério em relação às diferenças regionais do português ou buscou encontrar meio-termo e neutralidade na linguagem}

É interessante a pergunta. No meu caso, a experiência como tradutor de Quiroga partiu de minha pesquisa acadêmica sobre a obra dele, no fim dos anos noventa do milênio passado. A pesquisa propriamente não envolvia nenhum aspecto tradutório, mas passei a traduzir alguns contos do escritor, para conhecer de dentro o seu estilo, sua sintaxe, seu vocabulário. Posso dizer que foi uma experiência riquíssima, através da qual pude entender quanto havia de verdade naquela frase do Subirat. A tradução de Quiroga passou a ser uma forma privilegiada de conhecer a escrita dele, suas opções estilísticas. Apenas anos depois foi que comecei a traduzi-lo com vistas à publicação, atendendo a um pedido da Editora Iluminuras. Estamos falando já de meados da década passada. Naquele momento, o maior tradutor de Quiroga era o escritor Sergio Faraco, que traduzia para a L\&PM, com a clara opção pela variante do sul do Brasil. Lancei mão da variedade que falo da língua portuguesa: sou paulistano, e como se tratava, de traduzir os contos infantis do autor naquele primeiro momento - refiro-me aos livros Contos da Selva (2007) e Cartas de um caçador (2007) - busquei também uma linguagem que pudesse não soar estranha ao público leitor, formado principalmente por crianças e adolescentes. Já no caso dos Contos de amor de loucura e de morte (2013) foi preciso encontrar aquele ponto médio entre o contemporâneo e a literatura que traz ainda ecos do século 19. No entanto, minha opção foi sempre tornar a linguagem mais familiar ao leitor contemporâneo, urbano, do Brasil, incorrendo talvez em alguns regionalismos do sudeste brasileiro. Finalmente, na tradução, ainda inédita, de Os desterrados, livro de linguagem mais regional, busquei equivalentes do nosso universo rural. Nesse último livro, por exemplo, havia o desafio de traduzir as falas em portunhol presentes no conto que dá nome ao livro, e minha opção foi por uma forma de escrita que soasse familiar aos brasileiros e pudesse ecoar os termos hispânicos que estavam ali implicados. Em todos os quatro livros lancei mão de dicionários de botânica, zoologia, farmácia, biologia, enciclopédias e conversei com diversos profissionais das áreas, para poder dar com os nomes corretos de plantas, animais, solos, rochas que povoam o universo de Horacio Quiroga. 
Qual a importância de traduzir um autor como Quiroga, no Brasil contemporâneo?

Há uma grande falta de obras de Quiroga no Brasil ainda. Se por um lado há diversas traduções dos Contos de amor de loucura e de morte - quatro -, das Cartas de um caçador há somente a minha. A tradução de Os desterrados, que sai este ano, preencherá a lacuna da ausência de um século do mais importante livro do escritor. É preciso ir sanando essa falta. Estamos muito acostumados no Brasil a ler os escritores do boom latino-americano, o que leva a uma visão limitada do rico universo literário da língua espanhola.

\section{O que pode nos contar sobre suas pesquisas em relação ao portunhol na literatura?}

\section{Como definiria esse campo do saber?}

O portunhol pode ser tomado de muitas formas, por muitas áreas de pesquisa: a dialetologia, a socio-linguística, mas eu me aproximei dele justamente por conta de alguns contos de Quiroga, em que ele utiliza essa forma de escrita. Então o que sempre me interessou foi o portunhol da literatura. Há reflexões fascinantes sobre o campo, feitas pelo poeta Néstor Perlongher, por exemplo, que pensa no potencial da errância entre as línguas como gerador de significações riquíssimas. Ele faz isso no poema "Acreditando em Tancredo", por exemplo. Acredito que toda a reflexão de Jacques Lacan sobre a cadeia significante tal como surge no Curso de Linguística Geral de Ferdinand de Saussure, relida pela linguista Claudia Lemos, é muito produtiva. Há um veio importante aí a ser explorado. Temos já nosso cânone em espanhol no Brasil, partindo dos contos de Simões Lopes Neto, passando pelo Mar Paraguayo, de Wilson Bueno e, chegando, mais contemporaneamente, nos poemas de Douglas Diegues, que explora seu aspecto mais chistoso e disruptivo. Também eu passei da posição de pesquisador para a de poeta em portunhol, com meu livro em que misturo também outras línguas: Malangue Malanga (2019).

\section{Acredita que é possível traduzir o portunhol? Se sim, de que maneira?}

Referi-me acima à minha tradução de "Los desterrados", de Horacio Quiroga, na qual o que era importante passar do espanhol ao português a dimensão da presença da outra 
língua: o portunhol do original era destinado a produzir uma imagem do português na ortografia da língua espanhola. Tive que inverter isso, portanto. Em relação à poesia, lanço mão de um caso pessoal: o poeta venezuelano Jesús Montoya traduziu ao espanhol um poema meu escrito em portunhol, o poema 13 do livro Malangue Malanga, para a revista venezuelana Poesía (link aqui: http://poesia.uc.edu.ve/losbocarrotas/). O poema original tinha não apenas a mistura de línguas como também uma série de neologismos em torno ao tempo "impossibilidade". A estratégia do tradutor foi traduzir o que havia de espanhol para o português e vice-versa e lançar mão de novos neologismos a partir de sua leitura do poema. Nos termos de Haroldo de Campos, o que ele fez foi uma transcriação isomórfica, na qual se valeu das potencialidades do texto de partida, para uma criação paralela na língua de chegada. Valha uma curiosidade: produzi um áudio com as nossas vozes sobrepostas, lendo cada qual sua versão, e enchi o áudio de efeitos de reverberação, como forma de potencializar ainda mais a mistura (pode-se ouvir aqui: https://youtu.be/ie1x23jFPcA). Sempre se pode dar mais um passo.

Quando pensamos em América Latina, trocas culturais e memória histórica, que papel acredita que a tradução pode ocupar?

A tradução idealmente é um dos veículos para que a produção cultural, artística e intelectual possa cruzar as barreiras do idioma, as barreiras nacionais. É muito mais rico um intercâmbio direto entre nossos países que um intercâmbio mediado pelo hemisfério norte.

\section{Acredita que toda tradução é reflexo de uma postura reflexiva-teórica? Terias condições de definir a sua?}

Já terá ficado claro a esta altura que minhas principais referências são Haroldo e Augusto de Campos. Com a obra de ambos, a reflexão sobre a poesia, a tradução e a cultura brasileira chegam a outro patamar. Superamos nacionalismos ingênuos - como no Sequestro do barroco na Formação da Literatura Brasileira - lançamos mão de uma tradição ativa e inserimos no debate nacional poetas como e.e. cummings, James Joyce, Lewis Carroll, Rimbaud, relidos e recriados pelos Campos. Toda a reflexão de Haroldo de Campos sobre transcriação vale ouro. 


\section{O que define um bom tradutor? Quais são os nomes que mais se destacaram nestes}

últimos anos na América Latina?

Uma boa tradutora se define pelo pioneirismo e pela sensibilidade como texto, como no caso da querida Olga Savary, recém-falecida, que nos apresentou tantos textos fundamentais, como livros de Neruda, Paz, García Lorca etc. Hoje em dia, há tanta gente jovem traficando poesia de uma banda a outra do continente que em breves os efeitos serão sentidos. Paula Abramo, no México, acaba de publicar os contos completos de Clarice Lispector, promovendo novas possibilidades de estudo e focalização da obra da autora no hemisfério norte e já traduziu autores seminais como Raul Pompeia, Machado de Assis e contemporâneas como Angélica Freitas e Luiz Ruffatto, que é impossível ignorar sua importância na cena. Entre nós, Livia Deorsola tem traduzido autores hispânicos que chegam com atraso ao Brasil, como a contista argentina Silvina Ocampo e o mexicano Daniel Sada. Mas não podemos nos esquecer de tradutoras veteranas como Heloisa Jahn, Josely Viana Baptista e Maria Paula Gurgel Ribeiro e das novíssimas, como Meritxell Hernando Marsal e Beatriz Regina Guimarães Barboza.

\section{Observando a sua trajetória literária, a política é um ingrediente muito presente na poética, como definiria o seu papel de tradutor e a política?}

A militância de quem traduz pode se mostrar de muitas formas. Denise Bottmann, tradutora da língua inglesa, tem um blog importantíssimo, Não gosto de plágio http://naogostodeplagio.blogspot.com/ - cujo título é bastante eloquente e esclarecedor sobre seu papel. Aqueles de nós que têm condições de emplacar suas escolhas, de colocar para circular no Brasil livros que lhes parecem fundamentais e que estão ainda inexplicavelmente ausentes, fazem um grande papel político. Tradutores literários podem ser profissionais, mas também podem ser seres que querem fazer vingar uma obra, uma ideia, em seu próprio país. Um exemplo: para mim era fundamental que no Brasil bolsonarista de 2020 estivesse a obra feminista, provocativa e militante da poeta suíço-argentina Alfonsina Storni. Tomei isso como uma questão inegociável. É preciso 
que vozes de outros tempos e latitudes se voltem contra o arbítrio. Quem traduz tem um papel ativo nisso.

Considerando o seu ideal de tradução, existe alguma relação entre a sua condição de escritor e a de tradutor? Em que aspectos podemos considerar essa relação determinante?

Concordo com Haroldo de Campos, de que traduzir é recriar. Considero que houve muito trabalho de recriação na minha tradução de El Peletero, de Luis Gusmán, que virou Pele e Osso (2009). O mesmo me cabe dizer da recente tradução que publiquei de Alfonsina Storni, Sou uma selva de raízes vivas (2020). Por outro lado, os textos que traduzo me influenciam. Podem-se ver rastros de Pele e Osso no meu romance Vapor Barato, como da poética de Storni em alguns poemas meus como "O homem sem cabeça". Não fosse assim, que graça teria? 